Revista de la red interuniversitaria de estudios sobre las literaturas rioplatenses contemporáneas en Francia

$20 \mid 2019$

Situación

\title{
La novela y lo real, entrevista a Philippe Forest hecha por Laurent Zimmermann
}

Translator. Federico Calle Jordá

\section{CpenEdition}

\section{Journals}

Electronic version

URL: http://journals.openedition.org/lirico/8920

DOI: $10.4000 /$ lirico.8920

ISSN: 2262-8339

Publisher

Réseau interuniversitaire d'étude des littératures contemporaines du Río de la Plata

\section{Electronic reference}

"La novela y lo real, entrevista a Philippe Forest hecha por Laurent Zimmermann », Cuadernos LIRICO

[En línea], 20 | 2019, Publicado el 06 julio 2019, consultado el 02 junio 2020. URL : http://

journals.openedition.org/lirico/8920 ; DOI : https://doi.org/10.4000/lirico.8920

This text was automatically generated on 2 June 2020.

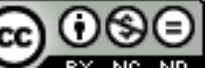

Cuadernos LIRICO está distribuido bajo una Licencia Creative Commons Atribución-NoComercialSinDerivar 4.0 Internacional. 


\section{La novela y lo real, entrevista a Philippe Forest hecha por Laurent Zimmermann}

Translation : Federico Calle Jordá

\section{EDITOR'S NOTE}

En nombre de Cuadernos LIRICO agradecemos a Laurent Zimmermann y a Philippe Forest la autorización para publicar esta traducción. Procedencia: http://www.fabula.org/ atelier.php?Le_roman_et_le_r\%26eacute\%3Bel. Las cursivas son siempre del autor. La traducción de las citas entre comillas siempre es del traductor. Las notas y comentarios del traductor irán entre corchetes.

Conocido por su importante obra novelística, Philippe Forest también es reputado por sus ensayos dedicados a la literatura, y ocasionalmente a la pintura y la fotografía. De hecho, del Niño eterno al Siglo de las nubes, sus novelas son respaldadas por una serie de obras teóricas, en particular, en la serie de los cinco Alaphbed publicados por las Ediciones Cécile Defaut, que de manera notable proponen una comprensión de la novela como confrontación con lo real y lo imposible, es decir, con una puesta a prueba del fracaso de la representación cuyo sentido será reformulado con precisión en esta entrevista. Es esto pues un recorrido con Philippe Forest, profesor de literatura francesa en la Universidad de Nantes, corredactor de la N.R.F. y colaborador asiduo de Art Press, para interrogar de nuevo la cuestión de la novela, las formas que propone como género, su sentido y las nociones importantes para pensarla (lo real, lo imposible, la heterografía). Es pues un recorrido junto a uno de los pensadores de la novela más importantes de hoy en día.

LZ 


\section{La novela y lo real}

1 Laurent Zimmermann: Usted ha escrito mucho sobre la novela. La primera pregunta que me gustaría hacerle tiene que ver precisamente con ello, y es muy amplia: ¿cómo define usted la novela?

Philippe Forest: La defino, lo reconozco, con ese giro un poco sistemático que caracteriza mi reflexión. Hace más de diez años, en 1999 para ser preciso, propuse en una conferencia que entonces se publicó como plaqueta y que de ahí en adelante sirvió como apertura a La novela, lo real y otros ensayos ${ }^{1}$, una definición de la novela que desde entonces he repetido tanto que casi se ha vuelto un slogan: "La novela responde al llamado de lo imposible real". Para mí no se trataba tanto de proponer una formula que valiera objetivamente para todas las novelas. Por cierto, como es sabido, y como Bakhtin en particular lo explica, una formula tal no existe, dada la formidable y perpetua plasticidad del genero. Más bien se trataba de destacar una concepción que aclara y le da sentido al proyecto de mis dos primeros textos de ficción: El niño eterno y Toda la noche. Aunque mis novelas ulteriores, de Sarinagara al Siglo de las nubes, sean bastante distintas, creo que aún corresponden a una idea idéntica. Del mismo modo, no hay que equivocarse en cuanto al sentido de la definición que propongo. No pretende dar con un denominador común de todos los textos que de ordinario se consideran novela. Intenta destacar una visión particular de la literatura, a la que reivindico y de la que me considero partícipe. Es una visión que hallo en algunos escritores, entre los cuales algunos, y hasta añadiría: casi todos, ni siquiera son novelistas. Pongo en la categoría "novela" a textos que, por su forma, ensayos o poemas, con evidencia no hacen parte de ella. Por el contrario, descarto a otros que, siendo relatos ficticios en prosa, tienen toda la apariencia de la novela. ¿Que interés tiene, si es que alguno tiene para alguien más que yo, semejante proposición? Se trata de volver a insistir, privilegiando lo que llamo "novela", en esa relación esencial que debe unir el "texto" con lo "real", dándole a estos dos términos el sentido que se les daba antaño, al que cabe recordar más aún en el contexto de regresión teórica actual. Sin dejar de interrogar por dentro su dimensión textual -es decir, cuando se toma a sí misma por objeto-, la novela, tal y como la concibo, debe estar encarada con una exterioridad que no es la "realidad" -en el sentido que le da a esa noción el neo-naturalismo que hoy renace- sino lo que en ella resiste a la representación. Es a eso que debemos llamar lo "real", o más bien, según Bataille, lo "imposible". Tal y como lo concibo, se trata pues de oponerle al "realismo" un "lo-realismo" 2 . Para los detalles de esta demostración, remito al texto que cité antes.

LZ: Hay algo como una paradoja en ciertas proposiciones que a veces usted formula con respecto a la novela 監 paradoja que tal vez tenga que ver con a una ambivalencia constitutiva de la novela. Usted dice a menudo que tiene apego por cierto nivel de construcción, por la disposición formal. Por eso, según dice usted, todo cuanto se parece al diario o al desarrollo de hechos en bruto (si es que eso es posible), no le interesa realmente como tal. Asimismo, usted suele insistir diciendo que todo lo que tiene que ver con la novela misma, considerada como objeto, expone la falta de sentido del mundo. ¿Diría usted que hay una contradicción en ello? ¿Habrían así dos direcciones contrarias que alternan la una con la otra? ¿O más bien diría que la construcción - es decir el esfuerzo por dar con un sentido que al mismo tiempo 
exponga lo real y su imposibilidad -, es, según usted, lo que podría constituir una definición aceptable de la novela?

Ph.F: De eso se trata, exactamente. La composición novelística -que por supuesto no es menor que la composición poética- existe precisamente para que aparezca ese vacío que hay en su centro, esa falla que no existe sino por el entorno de palabras e imágenes que la ciernen. Así pues, la posición que defiendo es de una banalidad impresionante, como de inmediato podrá notarlo cualquier persona un poco al tanto de lo que fue la literatura moderna. Véase al respecto lo que Lacan dijo sobre la obra de arte en La Ética del psicoanálisis, concepción con la cual de algún modo se relaciona toda la gran literatura del siglo pasado (como en Duras o en Leiris). Sin embargo, como todas las evidencias, esta tiende a ser olvidada periódicamente; es pues necesario recordarla hoy que triunfa, en el mercado si no en la universidad, una visión llanamente neonaturalista de la novela. La referencia esencial para mi es Bataille. Menos el Bataille de las novelas que el de los ensayos, el que explica como es necesario pasar por lo que el llama la "dramatización" para alcanzar ese lugar (el "punto de éxtasis") en el que la representación es abolida. Ese lugar en el que el sujeto experimenta la soberana puesta a prueba de la "experiencia interior" en algo como un vértigo que, si usted quiere, es el de la ausencia del sentido 跑 pero también el de su plenitud. En un texto corto bastante poco conocido, Julia Kristeva -basándose en los análisis anteriores que le dedica a Bataille y a Artaud, en el conjunto de lo que fue pensado por Tel Quel y alrededor de la ya lejana época de las vanguardias- llama a eso lo "verdareal" [vréel] lo verdadero, no como adecuación a la "realidad", sino como experiencia de lo "real". Esa es la clave.

5 LZ: Si hacemos un alto en la cuestión de la novela, se nos plantea el problema del reparto entre la ficción enfrentada al compromiso con lo que ha sido vivido realmente. Dos series de implicaciones se desdibujan. Empecemos por la primera. Se trata del cuestionamiento de la legitimidad propia de la ficción, al que usted a veces procede. ¿Diría usted categóricamente que la ficción ya no le parece capaz de poder renovar lo novela o de sostener novelas mayores, y que las obras que valen hoy en día se alejan necesariamente de ella?

Ph.F: Sería absurdo hablar contra la ficción y querer liberar de ella a la literatura, como si existiese una realidad pura que pudiese expresarse independientemente de toda forma de elaboración ficcional. Le ahorro la lista de buenos autores cuya autoridad podría ser convocada en este asunto: todos dicen que la realidad no existe sino en forma de ficción. Simplemente, defiendo la idea de que esta no tiene valor sino a condición de ser de algún modo un aval de la experiencia de lo real de la que hablé antes. Toda historia, incluso vivida, de algún modo, es inventada a partir del momento en el que se la relata. Lo que importa, es que permita el pasaje hasta ese lugar ignoto en que el lector y el autor llevan a cabo juntos la prueba de lo imposible. Por eso en uno de mis ensayos más recientes, La novela infanticida, para variar, usé adrede a Dostoievski, Faulkner y Camus como ejemplos, para demostrar como una novela, en el sentido más convencional del término, podía también responder a ese llamado de lo real que evoqué antes. Ahora bien, si los simulacros de la ficción son a la vez inevitables e incluso, en cierto sentido, indispensables para que ese llamado, de otro modo inaudible, con el que lo real se nos dirige, retumbe dentro del lenguaje, también puede suceder que esos mismos simulacros, en vez de abrir senderos hacia lo imposible, se transformen en algo así como una pantalla que impide acceder allí. Eso pasa cada vez que la ficción se encanta a sí misma, se pone a fabricar historiecitas en balde con sus estereotipos, cada 
vez que pretende sustraerse a la sanción final que da lo real y se declara 医 jcomo si fuera posible! 医 desligada de la vida. Remito de nuevo a Artaud ("No concibo la obra como desligada de la vida." ${ }^{3}$ ) o a Leiris (si bien es cierto que no hay escritor que en la página en blanco se enfrente al pitón del toro en sí, es sin embargo necesario que ese pitón proyecte al menos su sombra en la página o...). Así pues, aunque yo desde luego esté enterado del juego incesante que en la literatura se hace entre verdad y ficción, ese juego que las hace intercambiar perpetuamente sus puestos, por decirlo rápido y con una fórmula que necesitaría explicaciones mucho más extensas para no ser considerada como una idiotez completa o una ingenuidad total, poco importa, pienso que la verdad le gana a la ficción. Si usted quiere, jno soy un escritor posmoderno!

LZ: Falta le segunda serie de implicaciones, la que tiene que ver con el compromiso del "yo" en la novela y, por lo tanto, con cierta relación con la experiencia. Usted propone distinguir tres categorías, la "ego-literatura", la "autoficción" y la "Novela del Yo" o "heterografía". ¿Podría retomar estas categorías, en particular la tercera, con la distancia que le da la decena de años transcurrida desde el momento en que las propuso?

8 Ph.F: De nuevo: propuse ese modelito por razones del todo personales, para sacar a mis propias novelas de la lectura que de ellas prevalecía, y que por la dimensión autobiográfica y el carácter patético que tienen las acomodaba en los renglones de cierta literatura de lo vivido. Sin embargo, por haberlo puesto a prueba en muchos textos desde entonces, creo que ese modelo tiene un valor operatorio y explicativo bastante general. La expresión "Novela del yo" intentaba traducir literalmente la expresión "watakushi shôsetsu". En Sarinagara o en La belleza del contrasentido, intenté llamarle la atención a los lectores sobre el interés que tiene pensar la escritura personal partiendo del ejemplo muy lejano que nos da la literatura japonesa, en la que se despliegan modos de subjetivación distintos de los que podemos ver puestos en práctica en las Confesiones de Rousseau, obra de la que se nos intenta convencer de que es el alfa y el omega de toda empresa autobiográfica. El "yo (je)" obviamente se opone al "yo (moi) "4. El "Yo (je)" que escribe no es equivalente al "Yo (moi)" sobre el que escribe. De este modo se opera un desdoblamiento. En eso quise insistir con el título - “Je \& Moi” 医 que le di el año pasado al primer número de la NRF que dirigí desde que con Stéphane Audeguy tengo la corresponsabilidad de la revista. Tal como la concibo, la "Novela del Yo" incluye, digamos, tres estadios. Primero está la "ego-literatura" a la que el neonaturalismo reduce la escritura personal, limitándola así a una expresión de lo vivido. Luego está, según el neologismo de Doubrovsky, pero a partir de otras empresas literarias anteriores (Aragon en particular), la "autoficción"; empieza ahí donde la expresión de lo vivido se voltea sobre sí misma para tomar en cuenta su dimensión ficcional. Pero está sobre todo, y finalmente, lo que yo llamo, retomando una palabra del vocabulario de Bataille, la "heterografía": escritura de una alteridad radical que es, una vez más, aquella a la que nos confronta lo imposible dentro de esa "experiencia soberana" en la que el sujeto se hace y se deshace a la vez. De este modo, y por paradójico que parezca, el horizonte final de la "novela del Yo" se sitúa con respecto a una experiencia poética de lo impersonal. Debo remitir de nuevo a la demostración que se encuentra en La novela, lo real y otros ensayos, así como a algunas de mis intervenciones posteriores: en el coloquio sobre la autoficción organizado en Cerisy en 2008 por Claude Burgelin e Isabelle Grell, o al recentísimo coloquio sobre el mismo tema que tuvo lugar en Nueva York, dirigido por Camille Laurens y Tom Bishop. Digo que una idea semejante puede parecer paradójica. Al mismo tiempo, me parece que afirmar que 
la escritura del Yo (je) consiste en una ascesis en la que el sujeto se despoja de su yo (moi) para entregarse a la prueba de lo real, es una concepción que se halla dicha de manera literal en algunos de los mejores autores a los que se suele situar lindando con la autoficción, como Catherine Millet o Annie Ernaux, Catherine Millot y Camille Laurens.

9 LZ: A usted sin embargo no le interesa solo la novela. A pesar de algunas observaciones que en cierta medida podrían parecer recelosas hacia los poetas, a fin de cuentas la poesía nutrió toda una parte de su enfoque: está incluso presente en la simiente de su novela Sarinagara, puesto que el título y la idea de la obra provienen de un poema. Usted también ha escrito sobre pintura y fotografía. Aunque se sitúe en el interior mismo de la literatura (con la poesía) o en prácticas artísticas diferentes, ¿qué espacio tiene exactamente esa alteridad para su pensamiento y práctica de la novela?

Ph.F: Me reconozco bastante en esa frase en la que Caillois declara: "siempre me sentí más dispuesto a combatir la poesía que a entregármele". Siento el mismo recelo que él ante lo que considera, si recuerdo bien su expresión, como "un cheque en blanco endosado al misterio". La crítica que formula me parece muy justa 非en particular cuando se considera lo que a menudo se ha vuelto la poesía hoy en día. Ello no me impide leer y apreciar a poetas de ayer y hoy. Expreso mi posición en la primera parte de Sarinagara y en Haikus, etc., donde, por detrás de una discusión sobre poesía japonesa clásica y moderna, hablo en realidad de la poesía francesa contemporánea, rebatiendo cierto idealismo al oponerle, mediante la personalidad de Kobayashi Issa, una poesía de lo real. Esto ya era el sentido de los retratos paralelos de Hugo y Mallarmé que propuse en El niño eterno. De hecho, usted tiene absoluta razón, en mis novelas, en mis ensayos, siempre es al poeta, es decir al artista (y por ende al papel que le doy también a los fotógrafos japoneses como Yamahata o Araki) a quien le atribuyo esa experiencia de lo real en la que el sujeto experimenta el vértigo mismo de lo verdadero. Simplemente, a mí me parece que esta experiencia debe ser dicha y que no puede serlo sino en la lengua de la novela que lleva hasta ella. Es de nuevo la lección de Bataille: la representación es indispensable (si no, se cae en el mutismo o la mistificación) para ir hasta el punto en el que es abolida.

11 LZ: Evocaba en la pregunta precedente su práctica de la novela. Usted es uno de los pocos novelistas importantes, en Francia, que también es universitario. Con frecuencia las dos actividades son más bien distintas, e incluso contrarias. ¿Como concibe usted la(s) relación(es) y la(s) diferencia(s) entre las dos actividades? Asimismo, ¿diría usted que cada una de ellas sería distinta de lo que es si usted no practicase la otra? En particular, uno puede preguntarse si cierta dimensión de creación se impone en lo que atañe a la teoría, precisamente porque usted es novelista. Desde luego pienso, por ejemplo, en el más reciente de sus libros, Muchos días.

Ph.F: Me atrevo a decir que en la Universidad, poetas hay. Novelistas también debe haber. Pero es verdad que son menos frecuentes. Como se lo podrán confirmar todos mis colegas y estudiantes de Nantes, siempre me he esforzado en distinguir lo más sistemática y estrictamente posible esos dos papeles que desempeño alternándolos: el del profesor y el del escritor. Sin embargo, semejante línea de partición, por supuesto, es un artificio. En el fondo, es evidente que hay una gran porosidad entre la actividad crítica y la actividad creadora, a tal punto que se vuelve casi ilusorio distinguirlas la una de la otra, como lo explica Barthes en Crítica y verdad. Al contrario de lo que pretende cierto "positivismo" triunfante hoy en día, que propone moldear la enseñanza 
de las letras según la de las ciencias y las técnicas, un buen profesor de literatura, si no quiere aburrirse demasiado a si mismo y aburrir a sus estudiantes, debe contar con una subjetividad asumida, y desarrollar una visión personal de los textos que estudia y da a estudiar. Simétricamente, y a pesar del premio a la ignorancia que el mercado cultural le da a los escritores incultos, es obvio que un buen novelista es ante todo un gran lector que no puede ahorrarse el conocimiento sólido de la literatura, de su historia y de lo que en ella está en juego. Por todas estas razones, el crítico y el creador, el profesor y el escritor, coinciden. Desde luego, los protocolos son en cierta medida distintos y deben seguir siéndolo. Pero en el fondo, no tanto. Un buen ensayo, inclusive universitario, siempre es un relato, con su intriga, sus personajes, sus peripecias, y debe leerse como una novela. Incluso una buena novela, sobretodo si no es una novela que defienda una tesis, debe darle a su lector la impresión de que le está revelando una verdad, aunque sea esa verdad vacua que solo la literatura, porque raya en lo imposible, puede mostrar. De este modo todos los textos auténticos tienen que ver con esa tercera forma de la que hablaba Barthes, entre novela y ensayo. En cuanto a mí, he terminado por no distinguir demasiado la serie de mis ficciones novelísticas -del Niño eterno al Siglo de las nubes-, de la de mis ficciones críticas: la que incluye por supuesto el folletín de los cinco volúmenes publicados hoy por hoy con el título Alaphbed en la editorial Cécile Defaut, mis libros publicados en la colección "Arte y Artistas" e incluso mis otros trabajos, aunque se presenten bajo las especies aparentes de la seriedad académica. Estas dos series se desarrollan en paralelo y al mismo tiempo se impulsan, se responden la una a la otra, tanto así que de hecho son dos hebras tan íntimamente trenzadas que ya no son sino una. Usted mencionaba mi último libro, Muchos Días, que en efecto es un ejemplo total de semejante concepción. Se publica en las ediciones Cécile Defaut en una colección que dirige Isabelle Frell y cuyo título - "el libro de la vida"-, préstamo de Barthes, expresa bien el proyecto de una escritura oscilante entre novela y ensayo, entre discurso crítico y escritura personal. Es una obra que trata del Ulises de Joyce y puede ser leída como tal: según el modo objetivo de la guía o el comentario esclarecedor a esa gran novela, de la que sin razón se ha dicho que es muy difícil. Sin embargo, en la medida en que allí propongo una lectura subjetiva de la obra, también es algo así como una novela que se instala en la serie de las que he escrito. Es lo uno y lo otro. Pero en el fondo, siempre es así.

\section{NOTES}

1. [De Philippe Forest no están traducidas al español sino dos novelas: El niño eterno (Traducción de Hilda H. García, Serie Literaturas, Editorial del Estante, Buenos Aires, 2007) y Sarinagara (Traducción de Guido Sender, Sajalín Editores, Barcelona, 2009). Todos los otros títulos del autor son traducciones nuestras. No cuentan con traducción publicada.]

2. [Philippe Forest crea esta oposición a partir de la noción de "lo real" que en francés se dice "le réel"; la oposición en francés es entre réalisme/réelisme. Al no haber equivalente de esa distinción en lengua española, proponemos "lo-realismo" que permite retomar la lógica adversativa de Philippe Forest.] 
3. [Al ser Artaud, Leiris (y Caillois más adelante) citados de memoria por Philippe Forest, los traducimos literalmente, sin referirnos a las traducciones pre-existentes.]

4. [Confesamos no haber encontrado traducción de las nociones francesas de "je" y "moi" en lengua castellana. Las traducciones de Lacan al Ingles suelen remediar a esta arista vertiendo "moi" a "ego" y "je" a "I". Preferimos, en vez de inventar una operación similar, indicar entre paréntesis "moi" o "je" según la instancia que Philippe Forest designa en cada momento. El yo (je) designa pues el sujeto de la enunciación y el yo (moi) el sujeto del enunciado, según la distinción que realiza Philippe Forest. Dicho método es el que señala la traducción de Jorge Piatigorsky del Diccionario introductorio del psicoanálisis lacaniano de Dylan Evans, Buenos Aires, Paidós, 2003, p.197.] 